\title{
Regulatory Activities from Conjugated Linoleic Acid of p38 Protein in Melanoma Cells
}

\author{
Hyun Woo Kang*, Sang Jae Kwak \\ Department of Korean Food \& Culinary Arts, Youngsan University, Busan, Korea \\ *Corresponding author: khw7200@ysu.ac.kr
}

Received November 14, 2018; Revised January 24, 2019; Accepted March 02, 2019

\begin{abstract}
This study investigated the activities of trans10,cis12-conjugated linoleic acid (CLA) were then passed through the p38 in in vitro model. Cell viability, apoptosis, expression of p38 was evaluated using B16 melanoma cells. Our result showed that the trans10,cis12-CLA increased cell apoptosis in melanoma cells. In addition, CLA stimulated the expression of p38 and phosphorylation p38 (p-p38) level using western blotting. The p38 was presumed that the CLA were involved in regulation of apoptosis-related pathway in the melanoma cells signaling pathway. Considering the results obtained, the present study finding that the regulatory activities of trans10,cis12CLA may be important as a therapeutic target in ameliorating melanoma cells mediated cancer or/and tumor on in vitro model.
\end{abstract}

Keywords: conjugated linoleic acid, p38, melanoma cells, cell apoptosis

Cite This Article: Hyun Woo Kang, and Sang Jae Kwak, "Regulatory Activities from Conjugated Linoleic Acid of p38 Protein in Melanoma Cells.” Journal of Food and Nutrition Research, vol. 7, no. 3 (2019): 183-186. doi: 10.12691/jfnr-7-3-1.

\section{Introduction}

Melanoma is one of the most aggressive forms of skin cancer, with high metastatic potential and extraordinary resistance to cytotoxic agents [1,2]. Recently, about 3 million of non-melanoma skin cancers and over the hundred thousand melanoma skin cancers occur globally each year [3]. Despite extensive research and partial successes gained by use of various anti-cancer drug and immune research, currently there is no effective chemotherapy against invasive melanoma [4,5]. Therefore, it is necessary to develop new pharmaceuticals with potent activity against melanoma.

p38 mitogen-activated protein kinase (MAPK) is typically activated after cellular damage such as osmotic shock, stress or ionizing radiation, however, it also has an important role in a number of physiological processes, as well as being implicated in a number of different pathologies [6]. Typically, three kinds of MAPK family are the extracellularly responsive kinase (ERK), the c-Jun N-terminal kinase (JNK) and the p38 [8,9]. Early reported that p38 is a major intracellular signaling molecule critical to pigmentation, and p38 pathway activation has been reported to be related to an increase in melanin synthesis $[10,11]$.

CLA refers to a group of geometric and positional isomers of linoleic acid, which was originally identified as an anti-cancer component from ground beef extract $[11,12]$. A number of CLA isomers that differ in the positions of the double bound are possible [13].
Additional differences can exist in the configuration of the double bond so that cis-trans, trans-cis, cis-cis, or transtrans configurations are all possible. Early reported that the CLA have been shown to have variety physiological activities such as antioxidant [14,15] anti-inflammation [16,17], anti-cancer [18,19,20], anti-obesity [15], anti-carcinogenic [21], anti-hypertension [12] effects and reduction in the development of atherosclerosis [22,23]. Among them, CLA effect on anti-cancer or anti-tumor has extensively been studied. However, studies on the mechanism of melanoma cells are insufficient information. Therefore, our studies have used a mixture of CLA isomers with a major forms, trans10,cis12-CLA. Also, we were to determine the effect of trans10,cis12-CLA on the regulatory activity of p38 signal pathway in B16 melanoma in vitro model.

\section{Materials and Methods}

\subsection{Materials}

CLA was purchased from Matreya Inc. (State College, PA). B16 cells, the melanoma model for skin function studies, were obtained from the American Type Culture Collection (ATCC CRL-6475 ${ }^{\mathrm{TM}}$, Manassas, VA, USA). Dulbecco's Modified Eagle's Medium (DMEM) was obtained from COSMO BIO Co., Ltd., (Tokyo, Japan) and supplemented with $5 \%$ fetal bovine serum (FBS; Biological Industries, Kibbutz Beit Kaemek, Israel). 3-(4,5-dimethylthiazol-2-yl)-2,5-diphenyletrazolium bromide (MTT) (Logan, UT, USA). A propidium iodide (PI) 
Apoptosis Detection Kit I was purchased from BD Science (San Diego, CA, USA). Tween-20 was supplied by Novagen (Madison, WI, USA). Antibodies were purchased from Santa Cruz Biotechnology (Delaware, CA, USA). Also, an Enhanced Chemiluminescence (ECL) Advanced Detection Kit was obtained from Amersham Bioscience (Uppsala, Sweden). All other reagents were of the highest grade commercially available.

\subsection{Cell Culture}

The $\mathrm{B} 16$ cells were grown at $37^{\circ} \mathrm{C}$ in a used in $5 \% \mathrm{CO}_{2}$, 95\% air humidified atmosphere in growth medium consisted of DMEM supplemented with 5\% heat-inactivated FBS and antibiotics (i.e., $100 \mathrm{U} / \mathrm{ml}$ of penicillin, 100 $\mu \mathrm{g} / \mathrm{ml}$ of streptomycin) this study were used in no more than $10-13$ passages.

\subsection{Cell Proliferation Assay}

Cell viability was determined by using counting the number of cells. In brief, B16 cells were seeded at $1.0 \times 10^{4}$ cells per well in 24 -well plates in complete medium (i.e., DMEM with 5\% FBS) and incubated at $37^{\circ} \mathrm{C}$ for $24 \mathrm{hr}$. At the end of incubation period, and then the cells were treated with $1,5,10$ and $20 \mu \mathrm{M}$ of CLA in DMEM at $37^{\circ} \mathrm{C}$ for $72 \mathrm{hr}$. Cell proliferation was evaluated by counting the number of cells (ZI; Coulter Electronics, Hialeah, FL, USA).

\subsection{Measurement of Cell Apoptosis}

For sub-G1 and cell cycle analysis, B16 cells were suspended in ethanol with $0.5 \%$ Tween-20 and left for 24 $\mathrm{h}$ at $4^{\circ} \mathrm{C}$. The cells were harvested by centrifugation and resuspended in $1.0 \mathrm{ml}$ of PBS with $0.05 \mathrm{mg} / \mathrm{ml}$ of PI and $10 \mu \mathrm{g} / \mathrm{ml}$ of RNase A, and incubated at $37^{\circ} \mathrm{C}$ for $30 \mathrm{~min}$. Analysis of apoptotic cell death was performed by measuring the hypodiploid DNA contents using a flow cytometer (FACS-caliber; Becton Dickinson, Franklin Lakes, NJ, USA). The cells in the sub-G1 population were considered apoptotic cells, and the percentage of each phase of the cell cycle was determined.

\subsection{Western Blot}

To obtain the total cell lysate, $50 \mu \mathrm{L}$ of lysis buffer (50 $\mathrm{mM}$ Tris-Hcl, $150 \mathrm{mM}$ Nacl, $1 \mathrm{mM}$ EDTA, $50 \mathrm{mM} \mathrm{NaF}$, $30 \mathrm{mM} \mathrm{Na} \mathrm{P}_{2} \mathrm{O}_{7}$, and $1 \mathrm{mM}$ phenylmethylsulfonyl fluoride $2 \mu \mathrm{g} / \mathrm{mL}$ aprotinin) was added to the B16 cells $\left(3 \times 10^{5}\right.$ cells/mL) cultured in six-well plates. The cells were harvested, incubated for $10 \mathrm{~min}$ on ice and centrifuged at $12,000 \mathrm{rpm}$ for $10 \mathrm{~min}$ at $4^{\circ} \mathrm{C}$. The protein concentration was determined through the use the Bio-Rad DC protein assay, and $20 \mu \mathrm{g}$ of whole cell lysate was separated on $8 \%$ sodium dodecyl sulfate-polyacrylamide gels (SDS-PAGE). Electrophoresis was performed and the proteins were transferred to PVDF membranes using electro-blotting apparatus. These membranes were blocked with bovine serum albumin (Roche, Penzberg, Germany) for $1 \mathrm{~h}$ and then incubated overnight with primary antibodies diluted by 1:1000-5000 and immune complexes were incubated for an hour at room temperature with horseradish peroxidase-conjugated antibody diluted by 1:10000. After application of the secondary antibody, triplicate washes were followed with TBS-T, and developed for visualization using an ECL detection kit (Amersham Pharmacia Biotech, UK). The optical densities of the antibody-specific bands were analyzed through the use of NIH Image-J software (Bethesda, MD).

\subsection{Statistical Analysis}

Study data are expressed as mean \pm standard error of mean (SEM). Statistical analyses of differences between treatment groups were conducted using Student's $t$-test for paired data, and $p<0.05$ was considered to have statistical significance. All analyses were carried out in triplicate using Graph Pad Prism software version 4.00 (Graph Pad Software Inc., San Diego, CA).

\section{Results}

The effects of two kinds of CLA that the viability of melanoma cells were examined by counting the number of cells. B16 cells were treated with trans10,cis12-CLA at various concentrations $(0,1,5,10$ and $20 \mu \mathrm{M})$ for $72 \mathrm{~h}$. As shown Figure 1, cell proliferation was cytostatic activities by trans10,cis12-CLA up to $5 \mu \mathrm{M}$ on B16 cells. Data regarding the effects of CLA on cell proliferation B16 cells have not been reported previously and the mode of activity of CLA remains unknown. We were $5 \mu \mathrm{M}$ CLA selected for further study.

We further investigated the underlying basis of inhibit proliferation effects of CLA. Cell apoptosis analysis showed distribution in cell cycle, as shown in Figure 2, in the presence of non-treated CLA, the percentage of apoptotic cells observed were $2.49 \%$. The percentages of apoptotic cells observed was $10.91 \%$ for treated trans10,cis12-CLA (Figure 2). Therefore, these results indicate that cell apoptosis increased the treated trans10,cis12-CLA group. Cancer or/and tumor may be reduced by inhibiting cells growth or increasing apoptosis. CLA has anti-cancer or tumor activity such as MCF-7, MDA-MB-231, T47D, A-549, DLD-1, M4beu, PC-3, HT-29, Caco-2, MIP-101, SGC-7901 cell line [19]. However, melanoma inhibitory effect of CLA has a little information. Therefore, we showed trans10,cis12-CLA induced apoptosis in B16 cells.

MAPKs have been implicated in regulating the proliferation and differentiation of a variety of cells $[24,25,26,27]$. To determine whether MAPKs are involved in trans10,cis12-CLA, the impact of trans10,cis12-CLA on p-p38 was examined by western blotting, we canvassed the p38 following the treatment of these cells with 12 and $24 \mathrm{~h}$ on B16 cells (Figure 3). At the concentration of $5 \mu \mathrm{M}$, trans10,cis12-CLA for 12 and $24 \mathrm{hr}$ significantly reduced the p-p38 expression level by 37\%. However, cis9,trans11-CLA was without significant influence on p38 expressions in B16 cells (data not shown). Previous research reported that CLA are able to modulate the proliferation and differentiation of skeletal muscle cells trough MAPK pathway [28]. Ye et al [29] reported that pp38 was dose-dependently decreased by Chinese traditional herbal in B16 cells. In addition, Huang et al [30] 
research was show the p38 pathway in B16 cells and suggests that regulatory effect of melanoma. Consequentially, CLA are required in order to clarify this statement, the molecular mechanism responsible for the specific receptor of action and the bioavailability of trans10,cis12-CLA in melanoma cells.

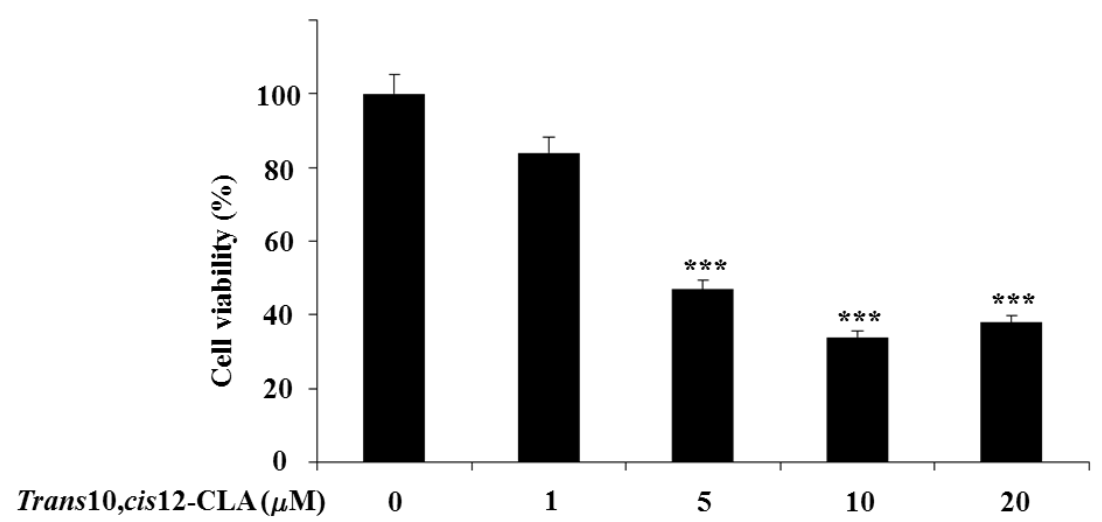

Figure 1. Effect of trans10,cis12-CLA on cell viability in B16 cells. Cell viability of B16 cells incubated with 0, 1, 5, 10 and 20 $\mu$ M trans10,cis12-CLA for $72 \mathrm{~h}$ determined. Data are presented as mean \pm S.E.M. $(\mathrm{n}=3)$ for three independent experiments. Significance was determined by Student’s $t$-test. ${ }^{*} p<0.05,{ }^{* *} p<0.01$ and ${ }^{* * *} p<0.001$.

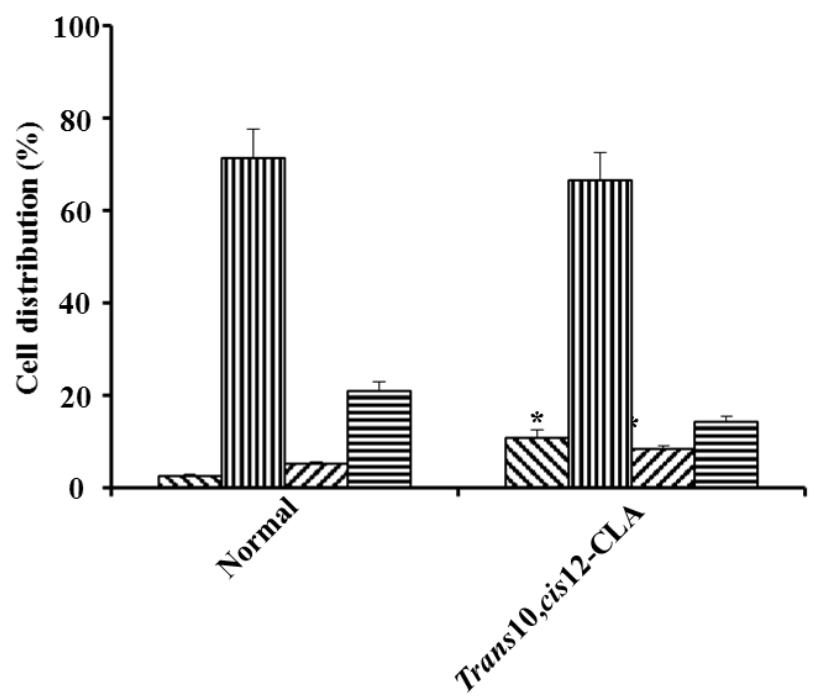

A Apoptosis

a G0/G1 phase

๑ S phase

E G2/M phase

Figure 2. Cell death and cell cycle of B16 cells after treatment with trans10,cis12-CLA treatment. Means \pm SD of determinations were made in triplicate experiments. ${ }^{*}(\mathrm{p}<0.05)$ and ${ }^{* *}(\mathrm{p}<0.01)$ are significantly different as analyzed by paired $\mathrm{t}$-test that compared the non-treated group

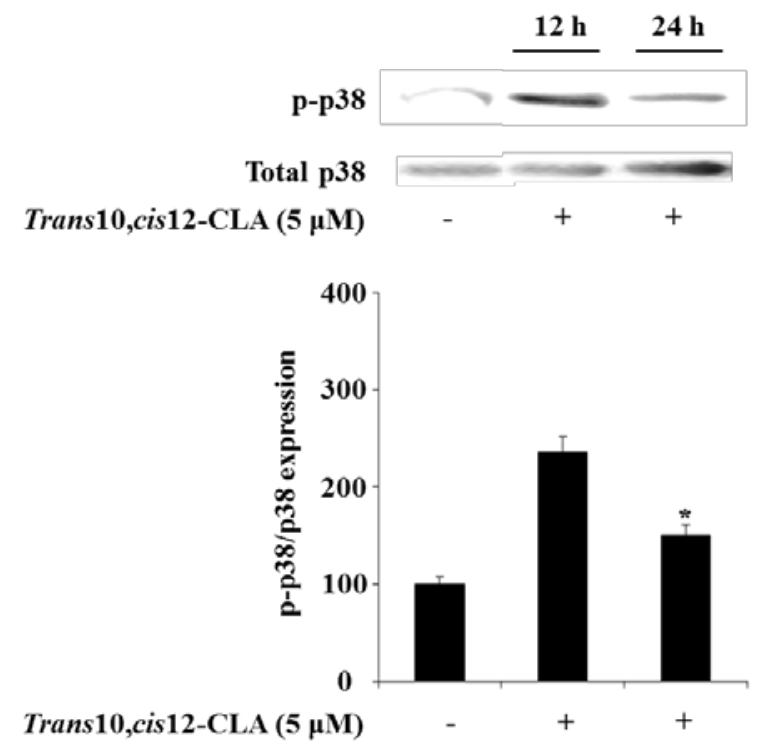

Figure 3. Phosphorylation levels of p38 by trans10,cis12-CLA during B16 cells. B16 cells were treated with CLA (5 $\mu$ M) for 12 and 24 hr, and phosphorylation level of p38 was examined by western blot analysis. All data were expressed as the mean \pm SD $(n=3)$. Statistical significance was analyzed by Student $t$ test. ${ }^{*} \mathrm{p}<0.05$. 


\section{Conclusions}

The major research study finding is that regulation of the p38 levels of MAPKs may be involved in the CLA-induced cytostatic of melanoma cells. As important, this CLA was analyzed for cell proliferation assay and protein expression by western blotting. It showed the highest melanoma B16 cells cytostatic activity compared with that of anti-cancer drug. In addition, trans10,cis12-CLA inhibit B16 cell proliferation and induce apoptosis. Based on these results, this trans10,cis12-CLA has the potential to be developed into new health foods and pharmaceuticals with potent activity against melanoma.

\section{Acknowledgments} 2018.

This research was supported by Youngsan University in

\section{References}

[1] Hoang, M.T., and Eichenfield, L. F., "The rising incidence of melanoma in children and afolescents”, Dermatology Nursing 12(3), 192-193. 2000.

[2] Duan, Y., Zhang, H., Xu, F., Xie, B., Yang, X., Wang, Y., and Yan, Y., "Inhibition effext of procyanidins from lotus seedpod on mouse B16 melanoma in vivo and in vitro" Food Chemistry 122(1), 84-91. 2010.

[3] Navarini, A.L.F., Chiaradia, L.D., Mascarello, A., Fritzen, M., Nunes, R.J., Yunes, R.A., Creczynski-Pasa, T.B., "Hydroxychalcones induce apoptosis in B16-F10 melanoma cells via GSH and ATP depletion”, European Journal of Medicinal Chemistry 44(4), 1630-1637. 2009.

[4] Legha, S.S., Ring, S., Eton, O., Bedikian, A., Buzaid, A.C., Plager, C., and Papadopoulos, N., "Development of a biochemotherapy regimen with concurrent administration of cisplatin, vinblastine, dacarbazine, interferon alfa, and interleukin-2 for patients with metastatic melanoma”, Journal of Clinical Oncology 16(5), 1752-1759. 1998.

[5] Sun, W., and Schuchter, L.M., "Metastatic melanoma”, Current Treatment Options in Oncology 2(3), 183-191. 2001.

[6] Nebreda, A.R., and Porras, A., "P38 MAP kinases: beyond the stress response”, Trends Biochemical Sciences 25(6), 257-260. 2000.

[7] Seger, R., and Krebs, E.G., "The MAPK signaling cascade", The FASEB Journal 9(9), 726-735. 1995.

[8] Cohen, P., "The search for physiological substrates of MAP and SAP kinases in mammalian cells” Trends in Cell Biology 7(9), 353-361. 1997.

[9] Singh, S.K., Sarkar, C., Mallick, S., Saha, B., Bera, R., and Bhadra, R., "Human placental lipid induces melanogenesis through p38 MAPK in B16F10 mouse melanoma”, Pigment Cell and Melanoma Research 18(2), 113-121. 2005.

[10] Hirata, N., Naruto, S., Ohguchi, K., Akao, Y., Nozawa, Y., Iinuma, M., and Matsuda, H., "Mechanism of the melanogenesis stimulation activity of (-)-cubebin in murine B16 melanoma cells”, Bioorganic and Medicinal Chemistry 15(14), 4897-4902. 2007.

[11] Pariza, M.W., and Hargraves, W.A., "A beef-derived mutagenesis modulator inhibits initiation of mouse epidermal tumors by 7,12-dimethylbenz[a]anthracene”, Carcinogenesis 6(4), 591-593. 1985.

[12] Park, Y.H., Albright, K.J., Storkson, J.M., Liu, W., and Pariza, M.W., "Effects of dietary conjugated linoleic acid (CLA) on spontaneously hypertensive rats”, Journal of Functional Food 2(1), 54-59. 2010.
[13] Seçkin, A.K., Gursoy, O., Kinik, O., and Akbulut, N., "Conjugated linoleic acid (CLA) concentration, fatty acid composition and cholesterol content of some Turkish dairy products”, LWT - Food Science and Technology 38(8), 909-915. 2005.

[14] Park, H.G, Heo, W., Kim, S.B., Kim, H.S., Bae, G.S., Chung, S.H., Seo, H.C., and Kim, Y.J., "Production of conjugated linoleic acid (CLA) by Bifidobacterium breve LMC520 and its compatibility with CLA-producing rumen bacteria”, Journal of Agricultural and Food Chemistry 59(3), 984-988. 2011.

[15] Evans, M.E., Brown, J.M., and McIntosh, M.K., "Isomer-specific effects of conjugated linoleic acid (CLA) on adiposityand lipid metabolism”, Journal of Nutritional Biochemistry 13(9), 508-516. 2002.

[16] Shen, W., Chuang, C.C., Martinez, K., Reid, T., Brown, J.M., Xi, L., Hixson, L., Hopkins, R., Starnes, J., and McIntosh, M., "Conjugated linoleic acid reduces adiposity and increases markers of browning and inflammation in white adipose tissue of mice”, Journal of Lipid Research 54(4), 909-922. 2013.

[17] Chung, S.K., Brown, J.M., Sandberg, M.B., and McIntosh, M., "Trans-10, cis-12 CLA increases adipocyte lipolysis and alters lipid droplet-associated proteins: role of mTOR and ERK signaling”, Journal of Lipid Research 46(5), 885-895. 2005.

[18] Park, Y.H., and Pariza, M.W., "Mechanisms of body fat modulation by conjugated linoleic acid (CLA)", Food Research International 40(3), 311-323. 2007.

[19] Kelley, N.S., Hubbard, N.E., and Erickson, K.L., "Conjugated linoleic acid isomers and cancer", The Journal of Nutrition 137(12), 2599-2607. 2007.

[20] Park, Y.H., "Conjugated linoleic acid (CLA): Good or bad trans fat?", Journal of Food Composition and Analysis 22S, S4-S12. 2009.

[21] Ip, C., Scimeca, J.A., and Thompson, H.J., “Conjugated linoleic acid: A powerful anticarcinogen from animal fat sources" Cancer 74, 1050-1054. 1994.

[22] Pariza, M.W., Park, Y.H., Cook, M.E., "The biologically active isomers of conjugated linoleic acid”, Progress in Lipid Research 40(4), 283-298. 2001

[23] Hur, S.J., Ye, B.W., Lee, J.L., Ha, Y.L., Park, G.B., and Joo, S.T., "Effects of conjugated linoleic acid on color and lipid oxidation of beef patties during cold storage”, Meat Science 66(4), 771-775. 2004

[24] Schramek, H., Sorokin, A., Watson, R.D., and Dunn, M.J., "Differential long-term regulation of MEK and of p42 MAPK in rat glomerular mesangial cells”, American Journal of Physiology 270(1 Pt 1), C40-48. 1996.

[25] Morisset, J., Aliaga, J.C., Calvo, E.L., Bourassa, J., and Rivard, N., "Expression and modulation of p42/p44 MAPKs and cell cycle regulatory proteins in rat pancreas regeneration", American Journal of Physiology 277(5 Pt 1), G953-959. 1999.

[26] Zhang, W., and Liu, H.T., "MAPK signal pathways in the regulation of cell proliferation in mammalian cells”, Cell Research 12(1), 9-18. 2002

[27] Yoo, M.S., Shin, J.S., Choi, H.E., Cho, Y.W., Bang, M.H., Baek, N,I., and Lee, K.T., "Fucosterol isolated from Undaria pinnatifida inhibits lipopolysaccharide-induced production of nitric oxide and pro-inflammatory cytokines via the inactivation of nuclear factor$\kappa \mathrm{B}$ and p38 mitogen-activated protein kinase in RAW264.7 macrophages”, Food Chemistry 135(3), 967-975. 2012.

[28] Lee, J.H., Tachibana, H., Morinaga, Y., Fujimura, Y., and Yamada, K., "Modulation of proliferation and differentiation of $\mathrm{C} 2 \mathrm{C} 12$ skeletal muscle cells by fatty acids”, Life Sciences 84(13-14), 415420. 2009.

[29] Ye, Y., Chu, J.H., Wang, H., Xu, H., Chou, G.X., Leung, A.K.M. Fong, W.F., and Yu, Z.L., "Involvement of p38 MAPK signaling pathway in the anti-melanogenic effect of San-bai-tang, a Chinese herbal formula, in B16 cells", Journal of Ethnopharmacology 132(2), 533-535. 2010.

[30] Huang, Y.C., Liu, K.C., Chiou, Y.L., Yang, C.H., Chen, T.H., Li, T.T., and Liu, L.L., "Fenofibrate suppresses melanogenesis in B16-F10 melanoma cells via activation of the p38 mitogenactivated protein kinase pathway”, Chemico-Biological Interactions 205(3), 157-164. 2013. 